\title{
The Influence of a Pneumoperitoneum on a Cardio- Vascular System and Central Hemodynamics in the Medical Cases of Robotic and Laparoscopic Gynecological Surgeries
}

\author{
Kameliya Tsvetanova \\ Doctor G. Stranski "University General Hospital for Active Treatment Plc-Pleven Town-Clinic of Anesthesia and Intensive Therapy-III- \\ Ward for Anesthesia and Intensive Care
}

\begin{abstract}
Background: High technologies in medicine enter more widely surgical practice. Their main goals are the achievement of greater precision, the alleviation of pain and the reduction in complications and improvement in the patient's quality of life during a post-operative period. Robotically-assisted surgery performed with Da Vinci surgical system is the most appropriate one. Aim: It is to compare the following hemodynamic indices: systolic blood pressure, diastolic blood pressure, a pulse rate, a heart rate and average blood pressure, during five consecutive stages of surgical intervention. Material and methods: 470 women took part in the conducted prospective medical research, as they suffer from gynecological diseases (benign and malign), but they have undergone surgery in the clinic of „Oncogynecology“ at "Doctor Georgi Stranski" University General Hospital for Active Treatment PLC for a period of 8 years (year 2007 - year 2015). Two groups of lady patients have been formed. The first group has undergone robotic (robotically-assisted) surgery - 223 women (47,4\%) and the second one, consisting of 247 women (52,6\%), was subject to laparoscopic surgical intervention. Results: The observed cardiovascular changes in both researched groups are similar, but are more expressed in the group of female patients, who have undergone surgery by means of Da Vinci robotically-assisted system.
\end{abstract}

Keywords: Cardiovascular complications, Laparoscopic surgery, Robotic surgery

\section{Introduction}

High technologies in medicine enter more widely surgical practice. Their main goals are the achievement of greater precision, the alleviation of pain and the reduction in complications and improvement in the patient's quality of life during a post-operative period.

Robotically-assisted surgery performed with Da Vinci surgical system is the most appropriate one. The introduction of this innovative surgical approach, however, tests the knowledge and the skills of the anesthesiologist, who must perform anesthesia in a unique surgical environment, associated with the creation of high intraabdominal pressure of approximately $20 \mathrm{mmHg}$ in the conditions of an extreme Trendelenburg position at $45^{\circ}$. The most frequently observed complications, which are recorded, concern a cardiovascular system.

Cardiovascular changes, taking place during this kind of surgical interventions, are due to the mechanical and chemical effects of a $\mathrm{CO}$-induced pneumoperitoneum.

It is proved, that the influence of increased intra-abdominal pressure upon hemodynamics depends on: the value of the higher intra-abdominal pressure and the degree of disturbance of the volume of a circulating fluid

(intravascular condition) and the initial condition of hemodynamics. [1]

The influence of a carbo-peritoneum upon a cardiovascular system is exerted by means of two different mechanisms. The first is due to the compression influence from increased intra-abdominal pressure on blood vessels in abdominal organs and the second mechanism is due to different vasoactive substances, whose release is caused by the abovementioned increased intra-abdominal pressure [2]

The influence of a carbo-peritoneum upon blood circulation is conditioned also by the effect of the absorbed $\mathrm{CO} 2$. [3] The postural reactions, at the moment of a change in a body position, in order to create comfortable conditions for surgery are also of some importance to the changes in hemodynamics.

The influence of all these factors is exerted in different areas and the final effect often depends on the patient's initial condition, the degree of the compensatory abilities of a cardiovascular system, the duration of a carboxi-peitoneum and so on.

The mechanical compression of v.cava inf. causes a decrease in venous return (an excessive load) and a reduction in a cardiac response. At the same time, the absorption of $\mathrm{CO}$, leading to an increased level of $\mathrm{PaCO} 2$, is able to stimulate the sympathetic trunk of the vegetative nervous system. It is expressed as an increase in a heart rate and arterial blood pressure.

\section{Aim}

It is to compare the following hemodynamic indices:systolic blood pressure, diastolic blood pressure, a pulse rate, a heart rate and average blood pressure, during five consecutive stages of surgical intervention (1. Before premedication, 2. After premedication and introduction to anesthesia at a horizontal body position, 3 . After the insufflation of $\mathrm{CO} 2,4$. At Trendelenburg position and 5. After the desufflation of $\mathrm{CO} 2$ at the end of the anesthesia at the time of the return of 


\section{International Journal of Science and Research (IJSR) \\ ISSN (Online): 2319-7064 \\ Index Copernicus Value (2013): 6.14 | Impact Factor (2015): 6.391}

patient's body to its initial horizontal position on the operating (surgical) table.

\section{Material and Methods}

470 women took part in the conducted prospective medical research, as they suffer from gynecological diseases (benign and malign), but they have undergone surgery in the clinic of „Oncogynecology“ at "Doctor Georgi Stranski“" University General Hospital for Active Treatment PLC for a period of 8 years (year 2007 - year 2015). Two groups of lady patients have been formed. The first group has undergone robotic (robotically-assisted) surgery - 223 women $(47,4 \%)$ and the second one, consisting of 247 women $(52,6 \%)$, was subject to laparoscopic surgical intervention.

The medically researched female patients has an average age of $45,35 \pm 8,14$ years, being within the age range of 30-69 years, out of whom $223(47,4 \%)$ have undergone robotic and 247 (52,6\%) - laparoscopic surgeries. (please, see a figure $1)$.

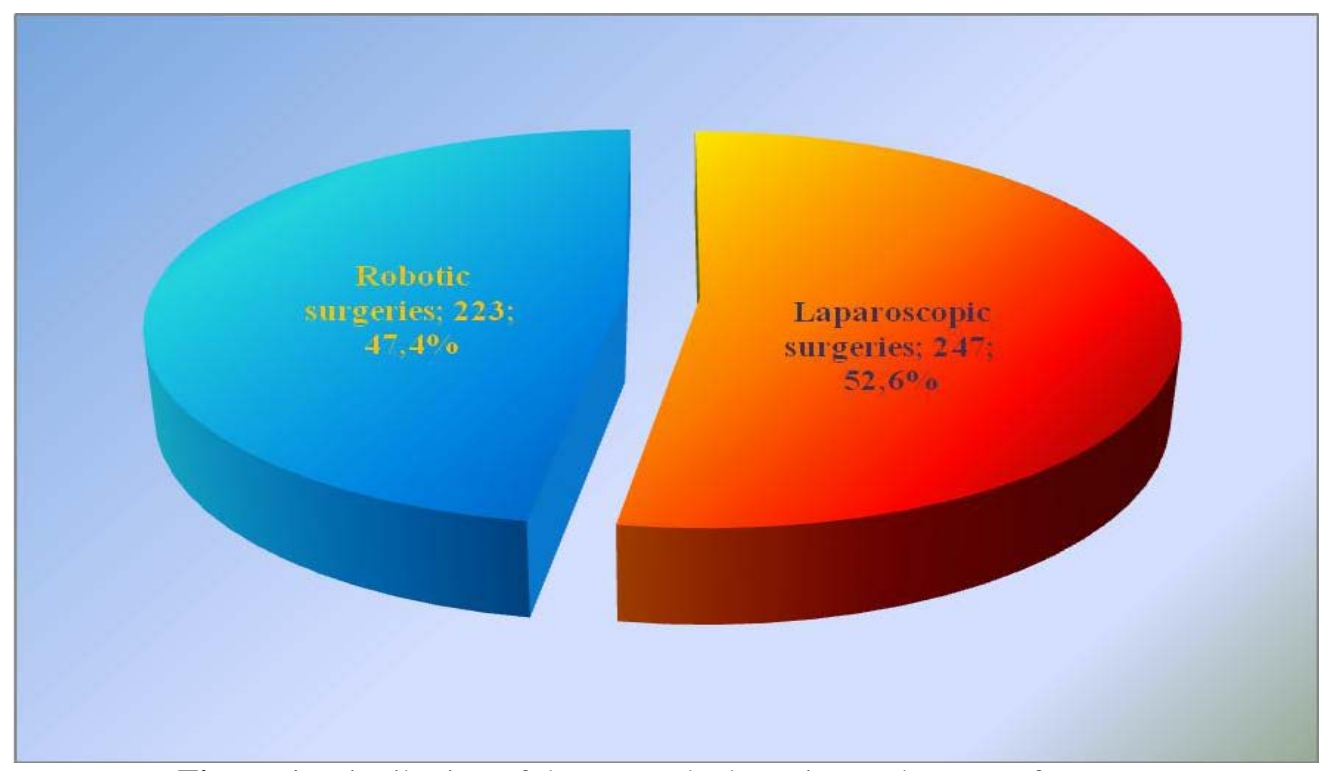

Figure 1: Distribution of the researched contingent by type of surgery

The greatest in number age group (78) in the case of robotic surgeries is 40-49 years, followed by 50-59 years with 65 and the smallest in number (18) - 60-69 years. In the case of laparoscopic surgeries, the biggest one in number (126) is the age group 40-49 years, followed by 30-39 years with 63 and the smallest one in number is 60-69 with five medical cases (please, see a figure 2).

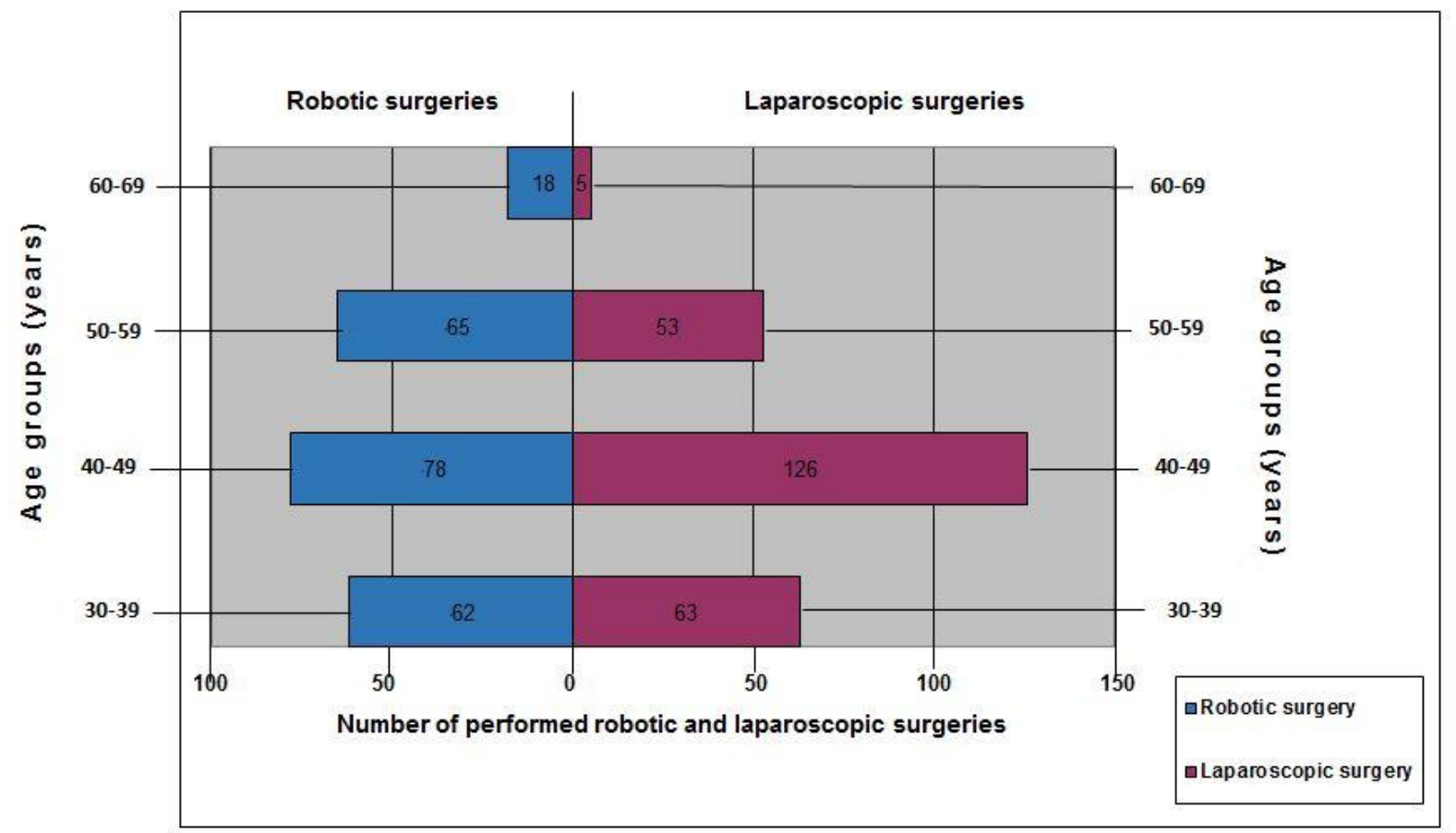

Figure 2: Distribution of the participants in the medical research by a type of performed surgery and age group. 


\section{International Journal of Science and Research (IJSR) \\ ISSN (Online): 2319-7064 \\ Index Copernicus Value (2013): 6.14 | Impact Factor (2015): 6.391}

It is established from the medically researched persons in the group of performed robotically-assisted surgeries, that 109 of the lady patients $(48,9 \%)$ are without concomitant diseases, as 114 of them, which represents 51,1\%, have diseases (Figure 3).

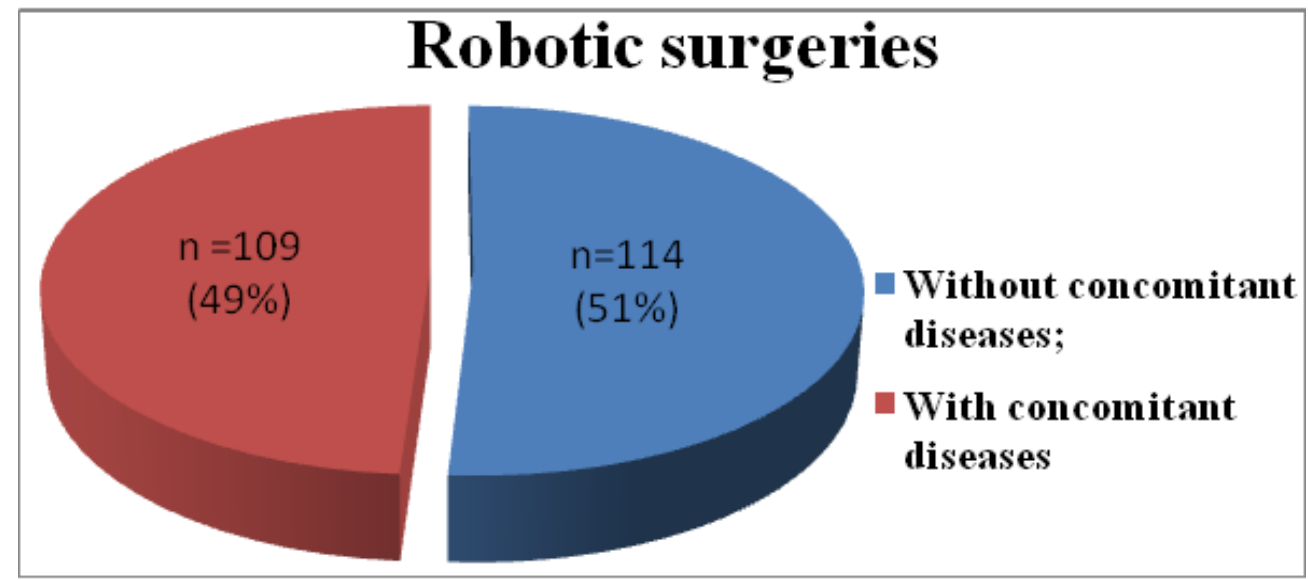

Figure 3: The frequency of female patients, who suffer from concomitant diseases, subjected to robotically-assisted surgery.

In the case of laparoscopic surgeries, 105 lady patients $(42,5$ $\%)$ are with concomitant pathology, as 143 of them $(57,5 \%)$ are without the presence of such. Graphically, this dependence is shown on a Figure 4.

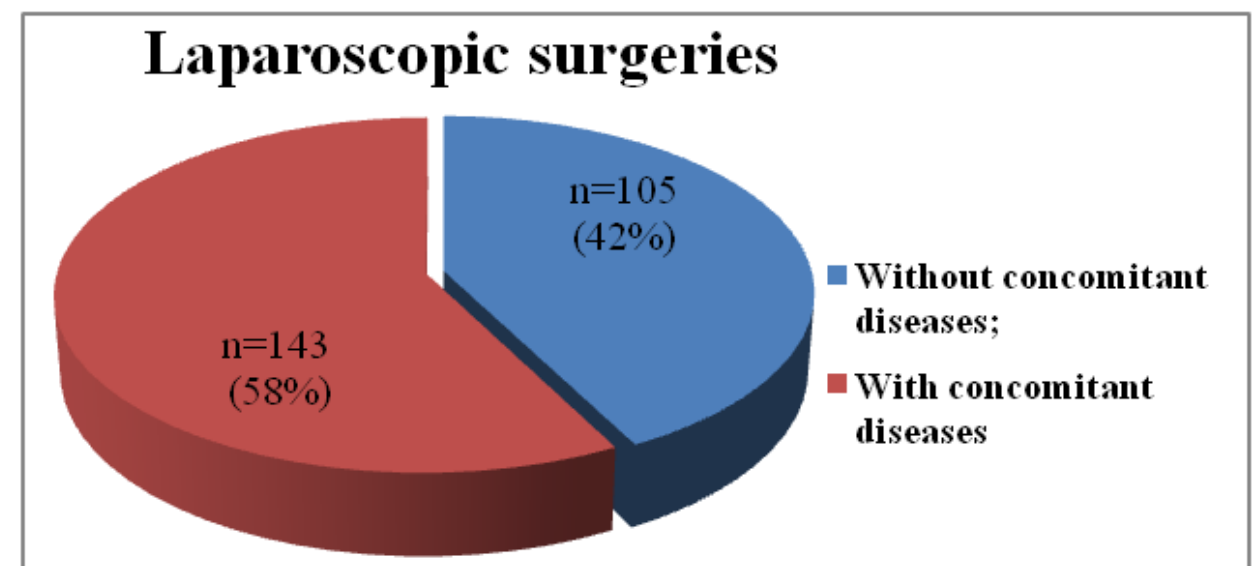

Figure 4: The frequency of female patients, who have concomitant diseases, but have undergone laparoscopic surgery.

At the time of laparoscopic and robotically-assisted surgeries, one traced five main stages in the course of anesthesia.

\section{Statistical Methods}

The data have been inserted and processed with SPSS 13.0 statistical software package. We have taken for granted $\mathrm{p}<0.05$, as a level of importance, on which one rejects the null hypothesis.

It is obvious from a table 1 , that:

- In the medical cases of female patients with laparoscopic surgeries, the statistically important diagnoses myoma utery and kysta ovarii dominate, while in the remaining cases - carcinoma colli uteri и carcinoma endometrii;

- The two medically researched groups do not differ statistically in terms of concomitant diseases, an introductory anesthetic + a depolarizing relaxant, an inhalation anesthetic and the need for blood transfusion;

- In the medical cases of lady patients with roboticallyassisted surgeries, one has applied considerably more the combinations dormicum + morphin as a medicament, used in premedication and arduan + fentanyl as a nondepolarizing relaxant + opioid analgesics, while in the laparoscopic group respectively - dormicum + fentanyl и tracrium + fentanyl. 


\section{International Journal of Science and Research (IJSR) \\ ISSN (Online): 2319-7064 \\ Index Copernicus Value (2013): 6.14 | Impact Factor (2015): 6.391}

Table 1: Frequency distribution of medically researched groups by means of a diagnosis, concomitant diseases, administered and taken anesthetics and the need for blood transfusion

\begin{tabular}{|c|c|c|c|c|c|}
\hline \multirow{2}{*}{ Indicators } & \multicolumn{2}{|c|}{ Robotically-assisted surgeries } & \multicolumn{2}{|c|}{ Laparoscopic surgeries } & \multirow[b]{2}{*}{$p$} \\
\hline & $\mathrm{n}$ & $\%$ & $\mathrm{n}$ & $\%$ & \\
\hline \multicolumn{6}{|l|}{ Diagnosis } \\
\hline Myoma uteri & 0 & 0,00 & 154 & 62,30 & $<0,001$ \\
\hline Kysta ovarii & 0 & 0,00 & 93 & 37,70 & $<0,001$ \\
\hline Carcinoma colli uteri & 155 & 69,50 & 0 & 0,00 & $<0,001$ \\
\hline Carcinom endometrii & 58 & 26,00 & 0 & 0,00 & $<0,001$ \\
\hline Carcinoma ovarii & 3 & 1,30 & 0 & 0,00 & n.s. \\
\hline Hyperplasia e olypus endometrii & 6 & 2,70 & 0 & 0,00 & n.s. \\
\hline Sarcoma uteri & 1 & 0,40 & 0 & 0,00 & n.s. \\
\hline \multicolumn{6}{|l|}{ Concomitant diseases } \\
\hline No & 109 & 48,90 & 142 & 57,50 & n.s. \\
\hline Yes & 114 & 51,10 & 105 & 42,50 & $\mathrm{n}$ s. \\
\hline \multicolumn{6}{|c|}{ Medicaments, administeredin the course of premedication } \\
\hline Dormicum + Morphin & 142 & 6 & 77 & 31,20 & $<0,001$ \\
\hline Dormicum + Fentanyl & 79 & 35,40 & 170 & 68,80 & $<0,001$ \\
\hline Diazepam + Morphin & 2 & 0,90 & 0 & 0,00 & n.s. \\
\hline \multicolumn{6}{|c|}{ Introductory anesthetic+de-polarizing relaxant } \\
\hline Dip ivan + Lysthenon & 218 & 97,80 & 239 & 96,80 & n.s. \\
\hline Thiopental + Lysthenon & 3 & 1,30 & 7 & 2,80 & n.s. \\
\hline C 1 psol + Lysthenon & 2 & 0,90 & 1 & 0,40 & n.s. \\
\hline \multicolumn{6}{|l|}{ Inhalation anesthetic } \\
\hline Sevorane & 104 & 46,60 & 117 & 47,40 & n.s. \\
\hline Isoflurane & 119 & 53,40 & 130 & 52,60 & n.s. \\
\hline \multicolumn{6}{|c|}{ Non-depolarizing relaxant + opioid analgesic } \\
\hline Tracrium + Fentanyl & 44 & 19,70 & 118 & 47,80 & $<0,001$ \\
\hline Arduan + Fentanyl & 135 & 60,50 & 67 & 27,10 & $<0,001$ \\
\hline Esmeron + Fentanyl & 1 & 0,40 & 6 & 2,40 & n.s. \\
\hline Pavulon + Fentanyl & 43 & 19,30 & 56 & 22,70 & n.s. \\
\hline
\end{tabular}

\section{Results and a Discussion}

The most discussed group of changes during a pneumoperitoneum in the conditions of Trendelenburg position in the course of minimally-invasive surgical interventions (robotically-assisted and laparoscopic surgeries) is the influence on a cardiovascular system, which most often is noticeable at the time of the change in hemodynamics. It is explicable, whereas these changes can endanger directly the life of patients, if one does not know them well.

The most frequent indicators, which attract interest in the course of anesthesia, are:

\section{Heart rate}

High intra-abdominal pressure appears to be the most important factor, contributing to circulatory instability. The increased in a reflex manner (reflectorially) vagal tone, at the moment of the excessive unfolding of a peritoneum, leads to bradycardia.

We also report similar changes. After the insufflation of $\mathrm{CO}_{2}$ in an abdominal cavity, the registered pulse rate exposes to view a trend towards a decrease. Its values remain at the same level in Trendelenburg position and statistically authentically increase at the end of the anesthesia after the desufflation of $\mathrm{CO}_{2}$, up to the level equivalent to that at the beginning.

The average value of this indicator, at the time of laparoscopic surgeries, is significantly higher than that at the time of robotically-assisted surgeries. (Tabl. 2)

In support of our results are also the results reported by Vanlan Darlong (2012), who registers and reports a decrease in a heart rate after induction during general anesthesia and the insufflation of $\mathrm{CO}_{2}$. At $45^{\circ}$ Trendelenburg position, the heart rate remains constantly low up to the moment of $\mathrm{CO}_{2}$ desufflation, when its values return to the ones at the beginning. [4]

We have taken for granted, that the lower value of this indicator in the case of robotically-assisted surgical operations is due to the above-mentioned high intraabdominal pressure, leading to a disturbed venous flow from lower body extremities and the excessive stretching of the above-stated peritoneum, that contribute to the observed changes. 


\section{International Journal of Science and Research (IJSR) \\ ISSN (Online): 2319-7064}

Index Copernicus Value (2013): 6.14 | Impact Factor (2015): 6.391

Table 2: Dynamics of the heart rate in both surgeries

\begin{tabular}{|c|c|c|c|c|c|c|c|c|c|c|c|}
\hline \multirow{2}{*}{$\begin{array}{c}\text { Type of } \\
\text { surgery }\end{array}$} & \multirow{2}{*}{$\begin{array}{c}\text { Number of } \\
\text { cases }\end{array}$} & \multicolumn{2}{|c|}{$\begin{array}{c}\text { Before } \\
\text { premedication }\end{array}$} & \multicolumn{2}{|c|}{$\begin{array}{c}\text { After premedication and introduction } \\
\text { to anesthesia at a horizontal body } \\
\text { position }\end{array}$} & $\begin{array}{c}\text { After the } \\
\text { insuflation of } \mathrm{CO}_{2}\end{array}$ & $\begin{array}{c}\text { At Trendelenburg } \\
\text { position }\end{array}$ & \multicolumn{2}{|c|}{$\begin{array}{c}\text { After the } \\
\text { desufflation of } \\
\mathrm{CO}_{2}\end{array}$} \\
\cline { 3 - 14 } & $\overline{\mathrm{X}}$ & $\mathrm{SD}$ & $\overline{\mathrm{X}}$ & $\mathrm{SD}$ & $\overline{\mathrm{X}}$ & $\mathrm{SD}$ & $\overline{\mathrm{X}}$ & $\mathrm{SD}$ & $\overline{\mathrm{X}}$ & $\mathrm{SD}$ \\
\hline Robotic & 223 & $82,59^{\mathrm{a}}$ & 14,54 & $77,73^{\mathrm{b}}$ & 11,03 & $74,47^{\mathrm{c}}$ & 11,44 & $75,37^{\mathrm{c}}$ & 11,36 & $83,95^{\mathrm{a}}$ & 10,53 \\
\hline Laparoscopic & 247 & $82,91^{\mathrm{a}}$ & 13,97 & $80,50^{\mathrm{b}}$ & 12,46 & $77,15^{\mathrm{c}}$ & 12,05 & $77,34^{\mathrm{c}}$ & 11,35 & $82,75^{\mathrm{a}}$ & 10,33 \\
\hline $\mathrm{p}$ & & 0,468 & & 0,010 & & 0,019 & & 0,056 & & 0,277 & \\
\hline
\end{tabular}

Systolic blood pressure, diastolic blood pressure, a pulse rate and average blood pressure

It is well-known that the functional stability of Trendelenburg position is conditioned by baroreceptors. This position dose not lead to serious hemodynamic changes in patients without concomitant diseases and who have a normal volume of circulating blood.

However, upon the increase in the angle of the surgical table by $30^{\circ}, \mathrm{CVP}$ and PCWP are on the rise and the stroke volume and the above-stated average blood pressure are reduced.

In the medical cases of patients with low systemic pressure and low peripheral vascular resistance, this positioning leads to serious disorders in average blood pressure.
In the course of the conducted by us research, the average blood pressure, as a sum of systolic and diastolic blood pressure, follows the changes in these two indicators. It holds also true for pulse pressure, which represents the difference between systolic and diastolic blood pressure.

In terms of both medically researched groups, the systolic blood pressure, diastolic blood pressure, pulse rate and average blood pressure have a significant fall after the introduction into anesthesia and the insufflation of $\mathrm{CO}_{2}$ and return to their initial values at the end of the abovementioned anesthesia after desufflation.

At the time of laparoscopic surgeries, the average value of the reviewed indicators in Trendelenburg position is significantly higher than the one of robotically-assisted surgeries. (Tabl. 3-6)

Table 3: Dynamics of the systolic blood pressure in both surgeries

\begin{tabular}{|c|c|c|c|c|c|c|c|c|c|c|c|c|}
\hline \multirow{2}{*}{$\begin{array}{c}\text { Type of } \\
\text { surgery }\end{array}$} & \multirow{2}{*}{$\begin{array}{c}\text { Number of } \\
\text { cases }\end{array}$} & \multicolumn{2}{|c|}{$\begin{array}{c}\text { Before } \\
\text { premedication }\end{array}$} & $\begin{array}{c}\text { After premedication and introduction to } \\
\text { anesthesia at a horizontal body position }\end{array}$ & \multicolumn{2}{|c|}{$\begin{array}{c}\text { After the } \\
\text { insuflation of } \mathrm{CO}_{2}\end{array}$} & $\begin{array}{c}\text { At Trendelenburg } \\
\text { position }\end{array}$ & $\begin{array}{c}\text { After the } \\
\text { desufflation of CO }{ }_{2}\end{array}$ \\
\hline & $\overline{\mathrm{X}}$ & $\mathrm{SD}$ & $\overline{\mathrm{X}}$ & $\mathrm{SD}$ & $\overline{\mathrm{X}}$ & $\mathrm{SD}$ & $\overline{\mathrm{X}}$ & $\mathrm{SD}$ & $\overline{\mathrm{X}}$ & $\mathrm{SD}$ \\
\hline Robotic & 223 & $131,43^{\mathrm{a}}$ & 18,42 & $112,68^{\mathrm{b}}$ & 15,79 & $107,77^{\mathrm{c}}$ & 13,54 & $110,45^{\mathrm{b}}$ & 13,34 & $122,77^{\mathrm{d}}$ & 13,87 \\
\hline Laparoscopic & 247 & $128,09^{\mathrm{a}}$ & 14,47 & $113,69^{\mathrm{b}}$ & 13,18 & $109,80^{\mathrm{c}}$ & 12,35 & $113,17^{\mathrm{b}}$ & 13,22 & $124,32^{\mathrm{d}}$ & 12,11 \\
\hline $\mathrm{p}$ & & 0,068 & & 0,200 & & 0,134 & & 0,042 & & 0,318 & \\
\hline
\end{tabular}

*- the same letters horizontally mean lack of statistically significant difference, while the different letters mark a statistically significant difference $(\mathrm{p}<0,05)$

Table 4: Dynamics of the diastolic blood pressure in both surgeries

\begin{tabular}{|c|c|c|c|c|c|c|c|c|c|c|c|}
\hline \multirow{2}{*}{$\begin{array}{l}\text { Type of } \\
\text { surgery }\end{array}$} & \multirow{2}{*}{$\begin{array}{l}\text { Number } \\
\text { of cases }\end{array}$} & \multicolumn{2}{|c|}{$\begin{array}{c}\text { Before } \\
\text { premedication }\end{array}$} & \multicolumn{2}{|c|}{$\begin{array}{l}\text { After premedication and introduction to } \\
\text { anesthesia at a horizontal body position }\end{array}$} & \multicolumn{2}{|c|}{$\begin{array}{c}\text { After the } \\
\text { insuflation of } \mathrm{CO}_{2}\end{array}$} & \multicolumn{2}{|c|}{$\begin{array}{l}\text { At Trendelenburg } \\
\text { position }\end{array}$} & \multicolumn{2}{|c|}{$\begin{array}{c}\text { After the } \\
\text { desufflation of } \\
\mathrm{CO}_{2}\end{array}$} \\
\hline & & $\bar{X}$ & SD & $\bar{X}$ & SD & $\bar{X}$ & SD & $\bar{X}$ & SD & $\overline{\mathrm{X}}$ & SD \\
\hline Robotic & 223 & $77,41^{\mathrm{a}}$ & 11,77 & $66,57^{\mathrm{b}}$ & 12,78 & $64,10^{c}$ & 12,65 & $65,66^{\mathrm{b}}$ & 13,35 & $73,28^{\mathrm{d}}$ & 11,15 \\
\hline \begin{tabular}{|l|} 
Laparoscopic \\
\end{tabular} & 247 & $76,92^{\mathrm{a}}$ & 9,82 & $67,23^{\mathrm{b}}$ & 10,93 & $65,89^{c}$ & 10,95 & $68,66^{\mathrm{b}}$ & 10,94 & $75,11^{\mathrm{d}}$ & 9,20 \\
\hline $\mathrm{p}$ & & 0,755 & & 0,406 & & 0,183 & & 0,016 & & 0,088 & \\
\hline
\end{tabular}

*- the same letters horizontally mean lack of statistically significant difference, while the different letters mark a statistically significant difference $(\mathrm{p}<0,05)$

Table 5: Dynamics of the pulse pressure in both surgeries

\begin{tabular}{|c|c|c|c|c|c|c|c|c|c|c|c|}
\hline \multirow[t]{2}{*}{$\begin{array}{l}\text { Type of } \\
\text { surgery }\end{array}$} & \multirow[t]{2}{*}{$\begin{array}{c}\text { Number of } \\
\text { cases }\end{array}$} & \multicolumn{2}{|c|}{$\begin{array}{c}\text { Before } \\
\text { premedication }\end{array}$} & \multicolumn{2}{|c|}{$\begin{array}{c}\text { After premedication and introduction } \\
\text { to anesthesia at a horizontal body } \\
\text { position }\end{array}$} & \multicolumn{2}{|c|}{$\begin{array}{c}\text { After the } \\
\text { insuflation of } \mathrm{CO}_{2}\end{array}$} & \multicolumn{2}{|c|}{$\begin{array}{l}\text { At Trendelenburg } \\
\text { position }\end{array}$} & \multicolumn{2}{|c|}{$\begin{array}{c}\text { After the } \\
\text { desufflation of } \\
\mathrm{CO}_{2}\end{array}$} \\
\hline & & $\bar{X}$ & SD & $\bar{X}$ & SD & $\bar{X}$ & SD & $\bar{X}$ & SD & $\bar{X}$ & SD \\
\hline Robotic & 223 & $53,76^{\mathrm{a}}$ & 13,15 & $46,02^{b}$ & 12,21 & $43,62^{\mathrm{c}}$ & 11,30 & $44,73^{b}$ & 9,70 & $49,67^{\mathrm{d}}$ & 10,28 \\
\hline Laparoscopic & 247 & $51,54^{\mathrm{a}}$ & 10,51 & $46,51^{b}$ & 9,74 & $44,42^{\mathrm{c}}$ & 9,78 & $44,47^{\mathrm{c}}$ & 11,37 & $49,25^{\mathrm{d}}$ & 10,56 \\
\hline $\mathrm{p}$ & & 0,151 & & 0,264 & & 0,331 & & 0,334 & & 0,351 & \\
\hline
\end{tabular}

*- the same letters horizontally mean lack of statistically significant difference, while the different letters mark a statistically significant difference $(\mathrm{p}<0,05)$ 


\section{International Journal of Science and Research (IJSR) \\ ISSN (Online): 2319-7064}

Index Copernicus Value (2013): 6.14 | Impact Factor (2015): 6.391

Table 6: Dynamics of the average blood pressure in both surgeries

\begin{tabular}{|c|c|c|c|c|c|c|c|c|c|c|c|}
\hline \multirow[t]{2}{*}{$\begin{array}{l}\text { Type of } \\
\text { surgery }\end{array}$} & \multirow{2}{*}{$\begin{array}{l}\text { Number } \\
\text { of cases }\end{array}$} & \multicolumn{2}{|c|}{$\begin{array}{c}\text { Before } \\
\text { premedication }\end{array}$} & \multicolumn{2}{|c|}{$\begin{array}{l}\text { After premedication and introduction to } \\
\text { anesthesia at a horizontal body position }\end{array}$} & \multicolumn{2}{|c|}{$\begin{array}{c}\text { After the } \\
\text { insuflation of } \mathrm{CO}_{2}\end{array}$} & \multicolumn{2}{|c|}{$\begin{array}{l}\text { At Trendelenburg } \\
\text { position }\end{array}$} & \multicolumn{2}{|c|}{$\begin{array}{c}\text { After the } \\
\text { desufflation of } \\
\mathrm{CO}_{2}\end{array}$} \\
\hline & & $\bar{X}$ & SD & $\bar{X}$ & SD & $\bar{X}$ & SD & $\bar{X}$ & SD & $\bar{X}$ & SD \\
\hline Robotic & 223 & $95,42^{\mathrm{a}}$ & 13,00 & $81,94^{\mathrm{b}}$ & 12,61 & $78,66^{\mathrm{c}}$ & 11,83 & $80,59^{b}$ & 12,53 & $89,78^{\mathrm{d}}$ & 11,04 \\
\hline Laparocopic & 247 & $93,97^{\mathrm{a}}$ & 10,39 & $82,72^{\mathrm{b}}$ & 10,79 & $80,53^{\mathrm{c}}$ & 10,50 & $83,50^{\mathrm{b}}$ & 10,43 & $91,51^{\mathrm{d}}$ & 8,97 \\
\hline p & & 0,308 & & 0,474 & & 0,142 & & 0,010 & & 0,128 & \\
\hline
\end{tabular}

*- the same letters horizontally mean lack of statistically significant difference, while the different letters mark a statistically significant difference $(\mathrm{p}<0,05)$

Unlike us, Lestar (year 2011) registers, records and reports an increase in average blood pressure at $45^{\circ}$ Trendelenburg position and the return to its initial levels at the end of anesthesia after desufflation. [5]

Our opinion is that, the concomitant pathology of the lady patients medically researched by us, which is noticeable for the robotic group in $51,1 \%$ of the cases and in the laparoscopic one $-42,5 \%$, can be a prerequisite for observed hemodynamic changes.

On the other hand, all persons ill with cardiovascular diseases, after the pre-operative consultation held with a cardiologist, underwent their therapy ( $\beta$-blockers, $\mathrm{Ca}^{++}$antagonists, diuretics, antihyperintensive drugs and others), including also on the morning in the day of a surgical operation. By means of this circumstance, we also explain the lack of intra-operatively developed asystole in both medically researched groups of patients.

Our assignment to compare the similarities and to report the differences in the two groups, which have attracted our interest, proves that the observed changes are more strongly present in the robotic group. It proves the great influence, which high intra-abdominal pressure and the gravitational forces at the extreme Trendelenburg position exert upon the patients, placed on an operating table.

The higher the above-stated intra-abdominal pressure is, the more expressed is the disturbance of the venous flow from lower extremities, which leads to expressed depression with respect to central venous pressure, arterial pressure, a heart rate, stroke volume and mean arterial pressure.

A series of scientific reports stipulate the fall in blood pressure and in peripheral vascular resistance, at the moment of induction, in the course of general anesthesia. [6] , [7], [8], [9], [10]

Most often, it is associated with direct myocardial depression and the vasodilating effect of anesthetics, together with the loss of sympathetic tone. [11]

The pre-operative preparation of the female patients in the above-mentioned robotically-assisted group, in view of the bigger volume of surgical intervention to which they are subjected, included also the use of X-Prep and a cleansing enema on the day before the surgical operation. The limited intake of liquids and the developed dehydration, although slightly expressed, have contributed to some extent to the developed hypotonia at some of them, even at lady patients, ill with hypertension for many years according to their anamnesis.

On the other hand, in $63,70 \%$ of the female patients, who have undergone robotically-assisted surgeries, premedication was provided in the combination of Morphine hydrochloride + Midazolam.

It is well-known, that Morphine hydrochloride is hydrophilic and reduces general water content in the organisms of adult people. It means that the volume within which the pharmaceutical is distributed is smaller and the pharmacological effect is greater. [12]

It is logical to assume, that its cardiac depressant effect, against the background of all above-stated factors, which aggravate hemodynamics, additionally conduces to observed hemodynamic changes.

\section{Conclusion}

Having this information in mind, we should conclude, that:

1) The observed cardiovascular changes in both researched groups are similar, but are more expressed in the group of female patients, who have undergone surgery by means of Da Vinci robotically-assisted system.

2) The concomitant pathology, cardiac depressants, age, the duration of surgical intervention and anesthesia are of great importance to observed unfavorable changes in a cardiovascular system.

3) The selection of anesthetic medicaments, having a cardiac depressant effect, must be carefully compliant with the medical condition of patients.

4) The higher intra-abdominal pressure and the clearly expressed Trendelenburg position create a prerequisite for more frequent hemodynamic changes, concealing a risk for the life of sick persons.

\section{References}

[1] Waschberg R.H., Sebastiano L.L.,Levine C.D. Narrowing of the upper abdominal inferior vena cava in patients with elevated intra-abdominal pressure //Abdom Imaging.-1998.-Vol.23,N.1-P.99-102.

[2] Laureano B.A., Andrus C.H., Kaminski D.L.Cardiovascular changes during laparoscopy. In: Rosental R.J., Fredman R.L., Phillips E.H. The 
Patophysiology of Pneumoperitoneum. Pringer 1998; 77-85.

[3] Nguyen N.T., Wolfe B.M: The physiologyc effects of pneumoeritoneum in morbidly obese. Ann Surg 2005; 241:219-226.

[4] Vandal Darlong, Nishad Poolayullathi Kunhabdulla, Ravidra Panndey, Chandralekha, Jyotsna Punj, Rakesh Garg, and Rajeev Kumar. Saudi J Anaesth. 2012 JulSep; 6(3):213-218.

[5] Lestar M., Gunnarson L., Lagerstrand L., Wiklund P., Odeborg-Wernerman S. Haemodynamic perturbations during robot assisted laparoscopic radical prostatectomy in $45^{\circ}$ Trendelenburg position. Anaesth Analg. 20011 Nov.113(5):1069-75.

[6] Péter Sárkany, Szabolcs Lengyel, Réka Nemes, Lívia Orosa, Dénes Páll,Csilla Molnár and Béla Fülesdi. Noninvasive pulse wave analysis for monitoring the cardiovascular effects of $\mathrm{CO} 2$ pneumoperitoneum during laparoscopic cholecystectomy-a prospective case-series study. BMC Anaesthesiology 2014, 14:98.

[7] O'Leary E, Hubbard K, Tomey W, Cunningam AJ: Laparoscopic cholecystectomy: haemodynamic and neuroendocrine responses after pneumoperitoneum and changes in position. Br J Anaesth 1996, 640-644.

[8] Turkistani AA: Cardiodynamic monitoring during laparoscopic cholecystectomy. Middle East Anesthesiol 2005, 18:435-439.

[9] Joris JL, Noirot DP, Legrand MJ, Jacquet NJM Lami ML: Hemodynamic changes during laparoscopic cholecystectomy. Br J Anaesth 1993; 70:621-625.

[10] Hömme R: Anesthesia for laparoscopic intervencions (German). Anesthesist 2011, 60:175-185.

[11] Wahba RW, Bëque F, Kleiman SJ: Cardiopulmonary function and laparoscopic cholecystectomy. Can J Anaesth 1995, 42:51-63.

[12] Ronby JJ, B. Eurin, P. Glasier et al. Hemodinamic and Metabolic Effect of Morphyne in the Critically. Ill. Circulation. 1981; 64:53-59. 